\title{
Ambiguity at the crossroads of psychiatry and demoralization: Reflections and possibilities
}

\author{
Renato D. Alarcón, MD, MPH \\ Emeritus Professor of Psychiatry, Mayo \\ Clinic College of Medicine, Rochester, \\ Minnesota \\ Honorio Delgado Chair, Universidad \\ Peruana Cayetano Heredia, Lima \\ PERÚ \\ USA
}

\begin{abstract}
Background and Objectives: The concept and the impact of Ambiguity in the complex field of all human transactions have been captured by the texture of Culture and its many faces across the world. It generates intense debates reaching even most if not all areas of Science, once considered an unchallengeable source of precision and clarity. This article deals with the role Ambiguity plays in contemporary Culture and in the current state of Medicine in general, and Psychiatry in particular, in spite of advances in basic, clinical and technology-based research and practice. Ambiguity affects psychiatric nosology, diagnosis, treatment, prognosis and outcome. Almost inevitably, Ambiguity leads to polarities, disagreements and conflict. Examples of each if these situations are presented. Not surprisingly, it also influences the emergence of Demoralization, a psychoexistential feature that, paradoxically can be both the acme of failure, and the pathway towards hope, an essential ingredient in the psychotherapeutic encounter. As the latter, Demoralization cannot be a "mental disorder", although its ambiguous nature contributes to a pervasive uncertainty. At the crossroads of Ambiguity, Psychiatry and Demoralization must look for a better level of communication as a way to lessen the impact of Ambiguity and make it not only a core, positive component of Psychiatry's role but also a favorable ingredient in Demoralization's effect on the trajectory of patienthood.
\end{abstract}

Received: 24 September 2012

Revised: 23 November 2012

Accepted: 19 December 2012

Presented as part of a Key Note Lecture, World Congress of Psychiatry, Buenos Aires, Argentina, September 22, 2011. 


\section{Introduction}

Culture as a repository of individual and collective expressions of identity ${ }^{1}$, and Psychiatry as the source of clinical efforts to protect and care for an individual and collective sense of wellbeing, order, stability and perdurability $^{2}$, share ultimately a number of areas of concern. In the manner of Walpole's declaration that "the world is a comedy to those who think and a tragedy to those who feel" 3 , culture entails the dynamic co-occurrence of many events in the everyday life of individuals and communities, the language exchanges, the sharing of traditions, beliefs and ethical principles, the sense of belonging in and agreeing on hierarchies, distribution of responsibilities, intra- and inter-group relationships. Culture sustains outer patterns of clothing, eating or spending, surviving in a world of skyscrapers and slums, and it also encompasses innermost experiences of meanings, behavioral styles, emotional expressions, values to preserve or sins to punish or expel ${ }^{4}$. Together, these concepts establish the idea of context in the life of individuals and communities. But ultimately, culture leads to the transcendental notion of identity ("who are we", "what makes us unique", "how did we get here") and its ethnic, racial, geographic or political features of ontological support ${ }^{5}$.

Psychiatry and its sister concept, Mental Health, represent in addition, a real aspiration to confront the negative and damaging experiences of illness or disease, conceived both as medical entities as well as existential labyrinths ${ }^{6}$. Yet, as elaborated as it is, Psychiatry also possesses the subtle, some would say fragile, nature of an epistemological compositum susceptible to weaknesses, mistakes and ambiguity. As such, it faces another entity, also made out of ambiguity: a patient, a human being seeking help when assaulted by demoralization, a complex, heterogeneous condition, perhaps the acme of a complex variety of ingredients.

This article's objective is to examine how the core nature of Psychiatry's conceptual, clinical and even heuristic fields deals intensely and continuously with a spectra of ambiguity and uncertainties in today's world. To do it, an exploration of the concept in different areas, and of Medicine and Psychiatry's controversies will be followed by an overview of the mental health/mental illness dyad, the dilemmas of mental health care and the ultimate, also ambiguous expression of Demoralization as an "entry ticket", a reluctant player, a bitter component of psychopathology, and an early prescription of hope leading to the clinical-psychotherapeutic encounter. Ambiguity plays, therefore, a role in both the reasons for help-seeking and the body of knowledge and practice that, also ambiguously, attempts to materialize aspirations of hope by the individual patients and their families. And the surrounding culture is indeed the main stage of human life in all its expressions, the scenario at times luminous and at times dark of everyday existence. It is also a script endlessly delineating the transactions between human beings and between them and nature, the voice, the attitudes and the actions of us all, players in the comedies and dramas of humankind.

\section{The realm of ambiguity}

Hamlet's To Be or Not To Be dilemma represents the universal essence of Ambiguity, nourished by doubt, denial and conflict. The claim that Ambiguity pervades every type of human transactions may not be exaggerated. It is present in the endless products of artistic creativity throughout history, where the enormous diversity of interpretations and opinions 
about works and their authors may lead to inconclusiveness and uncertainty. Ambiguity seems to be inherent to predictions, findings, explanations and other configurations of the economy and by the economists at local and global levels. And, for many, it is the essential ingredient (at times, the mark of success) in politics, evident in the elastic language of leaders of all persuasions, in their messages and promises, in their background maneuvering, their claims of purity and their apologies when found in the holes of corruption ${ }^{7}$.

There is also Ambiguity in the realm of Science, beyond and in spite of its claims to the contrary. While the use of different procedures to reach the same research objective, to confirm the value or veracity of a given principle is considered science at its best, the explanations offered, based of course on the essences of each procedure, point immediately to the ambiguity or, at best, duplicity (or multiplicity) of the mechanisms at play. On the other hand, the scientific literature is full of strong statements in defense of diametrically opposed views about many phenomena. The obligatory inclusion of a "Limitations" paragraph or subsection in the format of every research article points to the uncertain, provisional and even shaky nature of the findings, and the recognized need to prevent misuse or misinterpretations.

The great debates about practically every area of scientific research, permeating even sacred fields of precision such as Physics or Mathematics and evolving through the polarities of Science and Humanism ${ }^{8}$, reflect the vicissitudes inherent to Ambiguity's epistemological predominance. Ambiguity is present in physiology's explanations, ranging -in the case of neuroscientific topics- from contemporary quasi-phrenological approaches to the broader conceptions of neural circuits and connections. It is evident in the therapeuticadverse dichotomy of effects of every phar- macological agent. The ambiguous role of transmitters and receptors at the edge of the intersynaptic space or in the barriers erected by cell membranes, phenomena such as the "inhibition of inhibitors", a sort of a dialectical "negation of a negation" has all the attributions of Ambiguity and its paradoxes ${ }^{9}$. In short, the Ambiguity of Science can be represented by the "Yes, but...." mixed expression of skepticism and magnanimity, hesitation and softened rejection.

\section{Ambiguity in psychiatry}

Although historically justifiable, the origins of the psychiatric discipline had an early seal of ambiguity when assigned to witches or magicians, shamans and priests attempting to understand the mysteries of the mind through sortileges, rituals, esoterism and hyperreligiosity. Each period of history had its doses of dogmatism and rebelliousness, claims of possession of the "primary truth" about mental illness, the "real and conclusive" explanations of causality, almost always shortly followed by protests, regrets, rectifications and apologies. Five psychiatric "revolutions" (Pinel's, psychoanalysis, psychopharmacology, social/community movement, and neurosciences) in four centuries, with a multitude of iterations across the world ${ }^{10}$, reflect the changing scope, the sequential polarization of realities nourished in their transiency by a never absent Ambiguity.

The undeniable advances in basic, clinical and technology-based research in the psychiatry of the last four or five decades has not yet erased the ambivalence of the public and even the discipline's practitioners about the place of psychiatry in today's medicine. Its reputation reflects the same ambivalence, born out of the ambiguity of its pronounce- 
ments about etiology, pathogenesis, diagnosis, treatment, outcome and prognosis of a growing variety of mental disorders ${ }^{11}$. Public prejudices, collective waves of stigmatization, neglect, marginalization and exile of mental patients and their families ${ }^{12}$ are cause and effect of such ambiguity. Even Psychiatry's place vis-à-vis the rest of Medicine (is it a "medical specialty" or something very different?) becomes an issue, the residual claims of the extremist anti-psychiatry movement ${ }^{13}$ reminding the world of drastically opposite perspectives. Last but not least, the still fragmented (i.e., "multifaceted") conceptualization of mental health and mental illness as reaffirmation and failure, respectively, of a bio-psycho-socio-cultural and spiritual entity ${ }^{14,15}$ contributes to forge an uncertain if not unclear and truly ambiguous field of theory and practice.

Several authors have dealt with the issue of psychiatry's ambiguity. McHugh and Slavney ${ }^{16,17}$ have written eloquently about "passion-arousing polarizations" in the field, ranging from philosophical disputes to scientific debates. They start with issues of "definition" of our discipline, and coin the term "phenomenal world" as the realm of "personal consciousness" where signs and symptoms lie, the "disjunction between mind and brain" described as the "essential polarity" whose components, however, "can neither be fully integrated nor completely separated". The subsequent tensions between natural sciences and humanities are expressed in the complex nuances of two polarities the authors examine: Patient-Client and Autonomy-Paternalism. Furthermore, they reject the use of "unreflective acceptance of doctrinaire positions as a means of resolving ambiguity".

Efforts of giant thinkers, from Descartes to Popper or Eccles, and of many notable clinicians cannot go, however, beyond mere correlations, leaving unexplained (ergo, am- biguous) issues such as "the transformation of neural processes into mental states". According to Slavney and McHugh, the Aristotelian understanding and the Galilean explanation are still insufficient methods of analyzing clinical phenomena or "modes of reasoning" in psychiatry, thus remaining as complementary approaches. In turn, the consciousness-unconsciousness polarity is "resolved" by these authors celebrating the former as the "triumph of evolution... its development has freed human beings from reflex responses to their external environments and internal drives". Many other authors would disagree with this conclusion, based in no other reasons than the incomplete scope of current knowledge.

\section{Main topics of psychiatric Ambiguity}

The human condition, considered by scholars of different disciplines (philosophy, psychology, social sciences, ethics, etc.) as an essentially ambiguous entity ${ }^{18-20}$ emerges, therefore, as the main source of this feature in clinical psychiatry. The psychiatric patient, with his/her multifaceted, complex set of emotions, behaviors and cognitive processes, called symptoms, triggered by heterogeneous stressors, and strongly colored by personality and temperamental traits ${ }^{21,22}$ challenges every notion of cogency or comprehensiveness carried on by the practitioner and his/her professional background. In such context, the topics of psychiatric ambiguity, the foci of conflict and controversy but also the targets of needed interventions, can be grouped in the areas of nosology, diagnosis, treatment and prognosis.

\section{Nosology and Classification}

Contemporary psychiatric nosology is dealing with two models of classification 
that, in spite of "harmonization" efforts ${ }^{23}$ by the two organizations involved, World Health Organization (WHO,) sponsor of the 11th. edition of the International Classification of Diseases (ICD-11), and the American Psychiatric Association (APA,) working on the fifth version of the Diagnostic and Statistical Manual of Mental Disorders (DSM-5,) still confront philosophical, methodological and logistic differences -all, features of ambiguity. Proclaiming similar objectives, it is clear however, that the audiences and their levels of acceptance will differ in the light of political, socio-cultural and other considerations ${ }^{24}$. WHO's rules and the international agreements that sustain them give the organization a sort of administrative/bureaucratic power to dictate, for instance, meta-structural schemes, use of codes and valid comparative strengths in epidemiological and statistical work ${ }^{25}$. The first version of DSM was published in $1952^{26}$ but its world-wide success started with DSMIII about 30 years later ${ }^{27}$ when it was considered an emblematic symbol of yet, another "revolution". In fact, DSM-III, with all the merits gathered by its evolvement and implementation processes, was a modern presentation of the phenomenological approach and the categorical model postulated by European psychiatry (particularly German and French) since the first decades of the 20th. Century ${ }^{28,29}$.

The differences between ICD and DSM reside in many areas. The grouping and number of clinical entities is different, some of the names or labels do not coincide, the weight and priority of symptoms vary, and even the nomenclatures' use in different countries or regions of the world follows rules specific for each of them. ICD must be obligatorily used in all countries even more so in international transactions or exchanges, every country is supposed to sign official agreements to formalize it, and periodically update such documentation. DSM, on its side, has benefitted from the geo-political predominance of the United States, the systematic publicity and dissemination of its content, the pragmatic angle of the phenomenological and multiaxial approaches, and the efficacious translation to practically all languages in the world ${ }^{30}$. It is not surprising that the average clinician anywhere will feel the dilemmatic pressures implicit in a nosological system that must be used vs. another one that seems to be preferred internationally.

\section{Diagnosis}

The intense debates between the psychodynamic and the phenomenological diagnostic approaches reached their peak around the $60 \mathrm{~s}$ and $70 \mathrm{~s}$, not fortuitously coinciding with the beginning of work on DSM-III ${ }^{27}$. The then still strong psychoanalytic establishment in the U.S. criticized the descriptive, categorical and ultimately medical approach of the new nomenclature and its diagnostic implications. The aggressiveness of the American initiative, the "atheoretical" philosophy of the new system, the many new diagnostic entities, changes in clinical interview styles and emphases, the appearance of guidelines and novel diagnostic instruments, the arguments of "lack of familiarity" with the forthcoming terminology were powerful ingredients in these exchanges ${ }^{31}$. It can be said that while the debates may now be less heated, some of the topics remain as evidence of pervasive objections to the current diagnostic systems.

Furthermore, a newcomer has entered into these discussions, with strong claims and hegemonic aspirations: the neurobiological approach to diagnosis with the notion of "biomarkers" as its conceptual and heuristic flag, and a quasi-arrogant air of inevitability. If Psychiatry claims to be a medical discipline, advocates of this school of thought maintain, it will have to have, sooner or later, 
biological tests and indicators of diagnostic value. Genetics, biochemistry, neurophysiology and neuroimaging studies will eventually provide sufficient evidence to formulate diagnoses whose precise and laboratory-supported labels will fully justify the change of current, "obsolete" ones. The announcement of preparations for the development of a Research Diagnostic Criteria tool (RDoC) in parallel or closely following the introduction of DSM- $5^{32}$, adds expectation but also increases the ambiguity of the current systems and even more, the level of uncertainty and confusion among clinicians.

\section{Treatment}

Psychiatry's ambiguity in this terrain is characterized by the dissonance between claims of "comprehensiveness" on the one hand, and the quasi-abandonment of the practice of psychotherapy by a growing number of psychiatrists around the world, on the other. The latter phenomenon results in the increasing involvement in and dedication to psychotherapy by other mental health professionals ${ }^{33}$. This situation may create what some authors call an "identity crisis" for the psychiatric profession with an inherent, also growing ambiguity about the "scientific" vs. the "humanistic" seal of the discipline. The implications on the patients' reaction and the public's response to these transfigurations have yet to be precisely determined.

If the primary modalities of treatment are considered to be psychopharmacological and psychotherapeutic, the situation can become even more complicated by other issues. In psychopharmacology, doses and side effects of medications, the alarming use of polypharmacy, and the hopefully clarifying but still evolving role of pharmacogenomics add complexity to this type of treatment ${ }^{34,35}$. In psychotherapy, the existence of hundreds of "schools" and techniques, and the role of so- cial and cultural therapies ${ }^{36,37}$ may be, at times, disorienting and overwhelming to patients, families, trainees and practitioners.

\section{Prognosis and Outcomes}

It follows, from the analysis above, that a multitude of factors play a role in the prediction of clinical course and outcome of practically all psychiatric conditions, and that unfortunately such role may also be covered by a veil of ambiguity. Clinicians may pay attention to genetic factors as determining prognosis in some but not in all diagnostic entities. The impact of environmental factors remains unclear and difficult to estimate. The "need of further research" becomes an overused, at times futile, at times promising slogan in today's psychiatric and scientific world.

To complicate matters of ambiguity, the role of culture in all the areas delineated above, strengthens the heterogeneity of clinical data and the difficult-to-measure impact of variables such as language, religion, traditions, explanatory models, help-seeking patterns, interpersonal style and the like $\mathrm{e}^{1,4,5,38,39}$. Yet, the pace of recognition of such factors is slower than it should be. Culture is a complex reality influencing each and every step of human life, each and every aspect of the clinical work. Knowing the cultural background of a patient can help to depathologize behaviors, but culture can also be pathogenic and pathoplastic ${ }^{40}$ thus becoming at times an elusive factor in the clinician's work. The message and the role of culture is another ongoing topic in contemporary clinical psychiatry.

\section{Demoralization and Ambiguity}

The concept of Demoralization and its characterization as a "state of subjective incompetence and distress in adversity" ${ }^{41}$, the perception of threat or disruption of the 
meaningful connections among cognition, emotion and volition, was elaborated by Jerome Frank ${ }^{42}$ as part of his brilliant pioneering work in psychotherapy research. Frank considered Demoralization a central feature of help-seeking processes in psychiatry and psychotherapy, and conceptualized it as both a "boundary phenomenon" in the neuro-psychiatric field, and an "existential problem" in the life of patients. These approaches and their powerful clinical implications summarize as well the essentially ambiguous nature and understanding of Demoralization.

De Figueiredo defines "subjective incompetence" as a "self-perceived incapacity (SI) to perform tasks and express feelings" 41 . After dissecting the concept, exploring its eminently individualized roots and following the routes of its meaning and its impact, it becomes evident that the original point of SI's shaping up process is a growing sense of self-doubt, self-debates, extreme tentativeness, and failed searches for solutions, all consolidated into the broader and deeper state of cognitive and behavioral Ambiguity. The individual's self-image reflects distortions and transfigurations dictated by Ambiguity, his/her actions may be contradictory or inauthentic, volatile and constantly changing. Compromised decision-making abilities also convey this state of psychological instability. In short, Ambiguity can be both cause and effect of Demoralization, a sort of vicious circle that, however, can leave a "space of hope" or "window of opportunity" through which the patient (and his or her family) may jump into a search for treatment.

There is a debate as to whether Demoralization can or should be considered a clinical condition; in fact, it has been described as "the prevailing form of depression in people who are medically ill" 43 . However, it can be said that Demoralization encompasses all aspects of the experience of being ill -physical and psychological. Precisely because Demoralization can be, at any given moment, the source of a desperate yet hopeful (i.e. ambiguous), self-critical and acrimonious yet determined (i.e., ambiguous) help-seeking move, it can also be said that it precedes an established diagnostic status or can be just prodromic to depression, anxiety or instabilities, better characterized by nosological labels.

Distress can also follow Demoralization or be part of it, but it also covers a narrower scope of occurrences than, say, clinical depression in the patient's experience; it can be as well, a pre-condition nourished by Demoralization and evolved, later, into a diagnosable entity. As such, it can be measured as high or low and its role in symptom severity, adherence, motivation for therapy and treatment outcomes can be subject of further research $^{44,45}$. Considering it as a diagnostic condition, can weaken or make Demoralization lose its motivating role, present in spite of its originally negative nature.

The awareness of failure and its implication of powerlessness, being the prelude of a fatalistic nihilism, makes Demoralization a high risk factor in the clinical course of any psychiatric condition. On the other hand, it may induce a relatively active process of selfexamination, no matter the initial negative implications of such step. Actually, Demoralization does not have to be the first or most significant factor in the help-seeking phase that, fortunately, emerges at some point in the clinical evolution of the majority of psychiatric patients. Thus, the very ambiguity of the patient's self-deliberations can lead to some degree of motivation to seek advice or professional help. Furthermore, the cultural basis of Demoralization are undeniable ${ }^{46}$, and its dynamic interactions with resilience and hope, for instance, can provide a fascinating stage for comparative clinical research. 
In the psychotherapeutic encounter, Ambiguity continues to reign through the dichotomies outlined by Griffith and DSouza ${ }^{47}$. They are: Hope vs. Despair, Coherence vs. Confusion, Communion vs. Isolation, Agency vs. Helplessnes, Commitment vs. Indifference and Gratitude vs. Resentment. Patient and therapist will work together, following a "contractual model" 16 to disentangle the knots of Ambiguity ("existential postures",) either embrace or retreat from adversity but, in any event, give credibility to the dialectical (Frank would call it, rhetorical [48]) power of Ambiguity as both the source of Demoralization and the pathway towards Hope. Careful of not falling into a paternalistic style (i.e., emphasis on the "sick role"), which would almost certainly enhance the negative effects of Ambiguity, the therapist would rather reinforce autonomy as part of the patient's repertoire and a "return to wholeness" in Slavney and McHugh's terminology ${ }^{17}$.

\section{Discussion}

The main thesis of this article is that Psychiatry as a discipline, and Demoralization as a psycho-existential feature possess and deal with Ambiguity, described as both a cognitive meander and a sketchy emotional mix. The collisional potential of Ambiguity may contribute to Psychiatry's changing role in the health and medical field, and makes Demoralization an erosive factor as well as a reflective tool in the patient's clinical trajectory and in his/her contacts with mental health professionals. There is no question that Psychiatry devotes itself, by definition, to strenuous, almost heroic efforts to disentangle an immense set of ambiguities. Ambiguity involves dilemmas such as Homogeneity vs. Heterogeneity, polemics such as that of Sci- ence vs. Humanism, socio-political realities such as the benign neglect of Mental Health vis-à-vis Public Health, the illusions and tragedies of similarities in many different fields of inquiry ${ }^{49}$. Closer to us, Ambiguity is the embodiment of human behavior, that elusive object of our best clinical efforts; it populates our diagnostic gardens, runs through our clinical settings and our treatment reservoirs. Ambiguity has become the language of our everyday transactions with patients, families, administrators, legislators, other professions, and society at large. And, as paradoxical as it sounds, Ambiguity also provides a degree of cogency to the evolvement of Demoralization.

Let's not confuse Ambiguity with duplicity or hypocrisy, not even with inconsistency or ontological deficits. Ambiguity is above and beyond all of them, the result of rather complex conceptions and practices throughout history. It was, in fact, an early conclusion of Greek and Roman philosophers ${ }^{49,50}$ when talking about the being of man. It has been also mentioned as substantive to Science in general but, whether we like it or not, Psychiatry is not only science, will never be, which make it even more consonant with Ambiguity ${ }^{51}$. Others have said that Culture is also an ambiguous conglomerate of diversities and differences, finally coalescing into an overall system that cannot be other than ambiguous. Be that as it may, the examples are abundant.

The Science-Humanism debate reflects this view well ${ }^{8,49}$. Nobody would question Ramachandran's sincerity in talking about the similarities between the Buddhist monk's inner search and the scientist's pursuit of truth, but his affirmation that if man would disappear from the face of the world, "the orangutans would take over" 52 entails the ambiguity of proportionalities. Or when Llinás ${ }^{53}$ claims in Gospelian terms that man 
will truly be "the King of Creation," only to affirm later that "ethics is the result of a dialogue between the thalamus and the cortex". Even some would say that Kendler's rejection of the "obsolete Cartesian dualism" sounds ambiguous when reading about his proposal of "explanatory pluralism" 54 , or that Eisenberg's cogent critique of "brainless and mindless psychiatry" does not connect straightforwardly with his complacent acceptance of the inevitability of "genetic noise" 55 .

Ambiguity has a lot to do with what can be called "the illusion of similarities" in geographic, historical or cultural terms. The "pervasiveness of differences" is a reality that adds to the Ambiguity load in our discipline, and certainly in the experience of Demoralization. Ambiguity is Theodore Dalrymple telling us: "If you want your young people to develop character, have the courage of your inconsistencies!. Excoriate sin, especially in public places, but turn a blind eye to it when necessary -as it often is" ${ }^{\prime 56}$. Ambiguity crowds the speeches of even the most sincere of politicians, or the most faithful in the religious communities, particularly when attempting to extract themselves from dogma-determined affirmations. There is Ambiguity in statistics which, attempting to teach us how to interpret facts, supports confirmations and refutations on the same subject, shamelessly using similarly apodictic pronouncements for both. The Ambiguity of "equalities" even in the most egalitarian societies is impressive. To reiterate it, in clinical psychiatry, the long lists of differential diagnoses, the abuse of polypharmacy, the cascade of side effects or the uncertainties of prognostic statements reflect honest appraisals but also Ambiguity at their base. In turn, the tragedy of similarities in the outcomes of corruption or terrorism, violence or hypocrisy, financial crises or long wars, speaks unquestionably of the strength of Am- biguity in today's culture and of its impact on the mental health of people.

Is inequality at the root of Ambiguity? And, does Ambiguity inevitably lead to social problems as its negative sequelae, a sort of collective Demoralization?. Tony Judt ${ }^{57}$ seems to think so. First, he outlines the challenges: "Any conversation with students or schoolchildren will produce a startling checklist of anxieties. Indeed, the rising generation is acutely worried about the world it is to inherit. But accompanying these fears there is a general sentiment of frustration: 'we' know something is wrong and there are many things we don't like. But what can we believe in? What should we do?". And after reflecting on the damages of thinking "economistically", and saying that "what matters is not how affluent a country is but how unequal it is", this American thinker concludes:

Inequality is corrosive. It rots societies from within. The impact of material differences takes a while to show up: but in due course competition for status and goods increases: people feel a growing sense of superiority (or inferiority) based on their possessions: prejudice toward those on the lower rungs of the social ladder hardens; crime spikes and the pathologies of social disadvantages become ever more marked. The legacy of unregulated wealth creation is bitter indeed.

In short, Ambiguity comes in.

Is Ambiguity all bad?. This author would want to answer "No." As a cultural reality in Psychiatry's field, it offers a renewed opportunity for epistemological, experimental and clinical studies of extraordinary potential. With a "healthy skepticism" as a point of departure, psychiatry can use technological and educational approaches to explore the core and the boundaries of Ambiguity, considered not as a curse but as a stimulus in the endless 
look for better perspectives in a patient-centered approach to care. This applies also to a focused consideration of Demoralization in the journey of patients deciding to seek help. To agree with this reasoning may engender both a better acceptance of Ambiguity as part of deliberations on goals common to a variety of clinical disciplines, and in the pursuit of a strengthened solidarity with the patient.

Moreover, with Ambiguity as a premise, research in cultural psychiatry and mental health will enjoy a broader latitude, applying a healthy relativistic perspective to all topics under study. The measurement of items such as cultural identity, religiosity, family integration or community ethics will make thinner the threats of doubt and conflict -of Ambiguity. The recognition of cultural variables and their role in clinical presentations, levels of severity or actual pathological nature of given behaviors will put away ambiguous interpretations of specific manifestations. Diagnosis will become more precise as a function of adequate combinations of phenomenological, dynamic, behavioral, existential and sociocultural approaches. Multidimensional, well defined treatment will acquire a clearer meaning, a less ambiguous strategic connotation.

\section{Conclusions}

Like many other concepts in human history, Ambiguity has the positive implications of potential improvements, and the negative ingredients of confusion and loss. This applies to both Psychiatry and Demoralization in the context of this article, situating one and the other at the crossroads of disciplinary development and conceptual and clinical usefulness. Commenting on Medicine's historical dilemmas, Lewis Lapham, an original American thinker, writes:
The more interesting questions are epistemological. How do we know what we think we know? Why is it that the more information we collect the less likely we are to grasp what it means? Possibly because a montage is not a narrative, the ear is not the eye, a pattern recognition is not a figure or a form of speech. The surfeit of new and newer news comes so quickly to hand that within the wind tunnels of the 'innovative delivery strategies' the data blow away and shred. The time is always now, and what gets lost is all thought of what happened yesterday, last week, three months or three years ago. Unlike moths and fruit flies, human beings bereft of memory...tend to become disoriented and confused. I know no other way out of what is both the maze of the eternal present and the prison of the self, except with a string of words ${ }^{58}$.

The statement, in fact, outlines the benefits of communication at the interpersonal and collective levels ${ }^{59}$. Communication at its best contributes to distill ideas, clarify perspectives, share opinions, disseminate values and improve being and well-being. Psychiatry requires the benefits of a better communication to extract itself from the volatilities of Ambiguity, to soften confusing or selfish polemics and to sharpen key concepts and ideas. Communication will make the vicissitudes of Demoralization lean away from their ambiguous route and towards the reflective veneer of consistent help-seeking; furthermore, it will make possible a clean psychotherapeutic encounter, not a monotonous, unproductive exchange of ambiguities.

This "cleaning up" of our discipline and its wrongdoings or misgivings through a sincere and profound dialogue between professionals, patients, families and the society at large, has to do with Octavio Paz's view that our world, our civilization "is not a motionless essence, always the same, always iden- 
tical: it is a society inhabited by discord but also possessed by the desire of restoring unity, a mirror in which as we watch ourselves, we get lost and as we get lost, we rescue ourselves" $" 60$. This search must be impregnated by the ancient meaning of Nihilism, not the perverted nihilism of our time. At the risk of sounding, yes, ambiguous, I follow Dostoevsky who in several of his novels described nihilism as a force carrying the ideal of a "noble serenity" making us reach equanimity in the face of misfortunes ${ }^{61}$, a definition very close to the contemporary version of resiliency, not exactly the opposite but surely a strong antidote for Ambiguity.

Psychiatry as the discipline focused more than others on the study and management of Ambiguity, occupies an expectant position in the development of medical knowledge in general and clinical expertise, in particular, giving battle to misfortunes of many kinds, including the rough edges of Demoralization. In turn, Ambiguity must be considered less of an obstacle and more as a stimulus for a comprehensive set of research topics and management strategies in all the areas of psychiatric knowledge. Psychiatry is the "Science of Ambiguity", a body of problematic realities and vigorous promises in today's multicultural world.

\section{References}

1. Leighton AH. Culture and Psychiatry. Can J Psychiat 1981; 26: 522-529.

2. Leighton AH. Caring for mentally ill people: Psychological and social barriers in historical context. Cambridge, UK: Cambridge University Press; 1982.

3. Walpole H. (n.d.) BrainyQuote.com. Retrieved July 26, 2012 from BrainyQuote.com. Web site: http://www.brainy quote.com/quotes/h/horacewalp163240.html

4. Winthrop RH. Dictionary of concepts in Cultural Anthropology. Westport, CT: Greenwood Press; 1991.
5. Magris C. Vivere significa migrare: ogni identitá é una relazione. Conversazione con Édouard Glissant. Corriere della Sera, Gioveddi 1 Ottobre 2009; p. 50-51.

6. World Health Organization. The World Health Report. Mental Health: New understanding, New hope. Geneva: World health Organization; 2001.

7. Frank JD. Psychiatry, the healthy invalid. Am J Psychiat 1977; 134: 1340-1355.

8. Schwartz MA, Wiggins O. Science, Humanism and the nature of Medical Practice: A phenomenological view. Perspect Biol \& Medicine 1985; 28: 331-361.

9. Stiglitz, J. Globalization and its Discontents. London: Penguin Books; 2002

10. Shorter E. A History of Psychiatry: From the Era of the Asylum to the Age of Prozac. New York: John Wiley \& Sons; 1997. Lopez-Ibor Aliño JJ. La psiquiatría de hoy. Barcelona: Toray; 1975.

11. Searle JR. The mystery of Consciousness. New York: NY Rev Books; 1997.

12. Balsa AI, McGuire TG. Prejudice, clinical uncertainty and stereotyping as sources of health disparities. J Health Economics 2003; 22: 89-116.

13. Szasz TS. The Myth of Mental Illness, Rev. Ed. New York: Harper \& Row; 1974.

14. Engel GL. The need for a new medical model: A challenge for biomedicine. Science 1977; 196: 129-136.

15. Ghaemi N. The Concepts of Psychiatry: A pluralistic approach to the Mind and Mental Illness. Baltimore: Johns Hopkins University Press; 2003.

16. McHugh PR, Slavney PR. The Perspectives of Psychiatry, 2nd. Ed. Baltimore: Johns Hopkins University Press; 1998.

17. Slavney PR, McHugh PR. Psychiatric Polarities. Methodology \& Practice. Baltimore: Johns Hopkins University Press; 1987.

18. Bamforth I. Course of Illness. Lapham's Quart 2009; 2: 215-221.

19. Roth M, Kroll J. The Reality of Mental Illness. Cambridge, UK: Cambridge University Press; 1986.

20. Toulmin S. The multiple aspects of mental health and mental disorders. J Med Philosophy 1977; 2: 191-196.

21. Kirmayer LJ, Rousseau C, Jarvis GE, Guzder J. The cultural context of clinical assessment. In: Tasman A, Kay J, Lieberman JA, editors. Psychiatry, 2nd. Ed. Chichester, UK: John Wiley; 2003. 
22. Oldham JM, Skodol AE, Bender DS. The American Psychiatric Publishing Textbook of Personality Disorders. Washington DC: American Psychiatric Publishing; 2005.

23. Regier DA, Narrow WE, Kuhl EA, Kupfer DJ, editors. The conceptual evolution of DSM-5. Washington DC: American Psychiatric Publishing, Inc.; 2011.

24. Hyman S. Delivering DSM-5 into the 21st. Century. Lectiure presented at the Annual Meeting, American Psychiatric Association, Philadelphia, PA, May 8, 2012.

25. World Health Organization. Metastructure of ICD-11 Section V, Mental Disorders. Geneva, Switzerland, 2010.

26. American Psychiatric Association. Diagnostic and Statistical Manual of Mental Disorders, 1st. Ed. (DSM-I). Washington DC: American Psychiatric Association; 1952.

27. American Psychiatric Association. Diagnostic and Statistical Manual of Mental Disorders, 3rd. Ed. (DSMIII). Washington DC: American Psychiatric Press; 1980.

28. Jaspers K. General Psychopathology. Chicago, IL: University of Chicago Press; 1963.

29. Delgado H. Curso de Psiquiatría, 6a. Ed. Lima, Perú: Fondo Editorial, Universidad Peruana Cayetano Heredia; 1993.

30. Nathan PE. The DSM-IV and its antecedents: Enhancing syndromal diagnosis. In: Barron JW, editor. Making diagnosis meaningful: Enhancing evaluation and treatment of psychological disorders. Washington DC: American psychological Association; 2002.

31. Pulver SE. On the astonishing clinical irrelevance of Neurosciences. J Am Psychoanal Association 2003; 51: 755-772.

32. National Institutes of Mental Health. NIMH Research Domain Criteria, RDoC. NIMH website, August 20, 2012.

33. Luborsky L, Crits-Christoph P, Mintz J, Auerbach A. Who will benefit from psychotherapy? Predicting therapeutic outcomes. New York, NY: Basic Books; 1988.

34. EveRx Spring. The dangers of Polypharmacy. Web site ASCP, December 2008.

35. Mrazek DA. Psychiatric Pharmacogenomics. New York: Oxford University Press; 2010.

36. Standal SW, Corsini RJ. Critical incidents in Psychotherapy. Englewood Clifs, NJ: Prenice Hall; 1959.

37. Tseng WS, Streltzer J, editors. Culture and Psychotherapy: A Guide to Clinical Practice. Washington DC: American Psychiatric Publishing; 2001.

38. Alarcón RD, Frank JB, Williams M. Cultural Dynamics in Psychotherapy and Cultural Psychotherapies. Ingredients, processes and outcomes. In: Alarcón RD, Frank
JB, editors. The Psychotherapy of Hope. Baltimore, MD: Johns Hopkins University Press; 2012. p. 281-309.

39. Alarcón RD, Williams M. Cultural Concepts in Persuasion and Healing. In: Alarcón RD, Frank JB, editors. The Psychotherapy of Hope. Baltimore, MD: Johns Hopkins University Press; 2012. p. 88-106.

40. Alarcón RD, Foulks EF, Westermeyer J, Ruiz P. Clinical relevance of contemporary cultural psychiatry. J Nerv Ment Dis 1999; 187: 465-471.

41. De Figueiredo JM. Deconstructing Demoralization: Subjective Incompetence and Distress in Adversity. In: Alarcón RD, Frank JB, editors. The Psychotherapy of Hope. Baltimore, MD: Johns Hopkins University Press; 2012. p. 107124.

42. Frank JD. Persuasion and Healing. A comparative study of Psychotherapy (2nd. Ed.) Baltimore, MD: Johns Hopkins University Press; 1973.

43. Clarke DM. Depression, Demoralization, and Psychotherapy in people who are medically ill. In: Alarcón RD, Frank JB, editors. The Psychotherapy of Hope. Baltimore, MD: Johns Hopkins University Press; 2012. p. 125-157.

44. Kissane DW, Wein S, Love A, Lee XQ, Kee PL, Clarke DM. The Demoralization Scale: a reports of its development and preliminary validation. J Palliat Care 2004; 20: 269-276.

45. Mangelli L, Fava GA, Grandi S, Grassi L, Ottolini F, Pecelli P, et al. Assessing demoralization and depression in the setting of medical disease. J Clin Psychiatry 2005; 66: 391-394.

46. De Figueiredo JM. The law of socio-cultural demoralization. Social Psychiatry 1983; 18: 73-78.

47. Griffith JL, DSouza A. Demoralization and Hope in Clinical Psychiatry and Psychotherapy. In: Alarcón RD, Frank JB, editors. The Psychotherapy of Hope. Baltimore, MD: Johns Hopkins University Press; 2012. p. 158-177.

48. Jaspers K. The Nature of Psychotherapy: A critical appraisal (Trans. Hoening J, Hamilton MW. Chicago, IL: University of Chicago Press; 1964).

49. Alarcón RD. Science and Humanism: Dialogues towards a desirable Convergence. George Tarjan Lecture, Annual Meeting, American Psychiatric Association, Honolulu, Hawaii, May 17, 2011.

50. Geldard RG. Parmenides and the Way to Truth. Rhinebeck, NY: Monkfish Book Publishing Co.; 2007.

51. Aristotle. Nicomachean Ethics. Translated by Bartlett RC and Collins SD. Chicago, IL: University of Chicago Press; 2010.

52. Ramachandran VS. A Brief tour of Human Consciousness. New York: PI Press; 2004. 
53. Llinás RR. I of the Vortex. From Neurons to Self. Cambridge, MA: MIT Press; 2001.

54. Kendler KS, Parnas J, editors. Philosophical Issues in Psychiatry. Explanation, Phenomenology and Nosology. Baltimore: Johns Hopkins University Press; 2008.

55. Eisenberg L. Are genes destiny? Have adenine, cytosine, guanine and thyamine replaced Lachesis, Clotho and Atropos as the weavers of our fate? World Psychiatry 2005; 4: 3-8.

56. Dalrymple T. The quivering upper lip. Harper's Magazine, May 2009; p. 15-19.

57. Judt T. Ill fares the land. The New York Rev Books. April 29, 2010; p. 17-19.

58. Lapham LH. Notebook. Figures of Speech. Harper's Magazine, November 2012; p. 7-9.
59. Alarcón RD. Culture, cultural factor and psychiatric diagnosis: review and projections. World Psychiatry 2009; 8: $1-9$.

60. Paz O. La tradición liberal. In: Hombres en su Siglo. Buenos Aires: Seix Barral; 1984. p. 11.

61. Dostoievsky F. The Idiot. New York: Vintage Classics; 2003.

Corresponding author:

Renato D. Alarcón, MD, MPH

Emeritus Professor of Psychiatry,

Mayo Clinic College of Medicine,

Rochester, Minnesota, USA

Honorio Delgado Chair,

Universidad Peruana Cayetano Heredia,

Lima, Perú 